\title{
Açaí (Euterpe oleraceae) 'BRS Pará': A tropical fruit source of antioxidant dietary fiber and high antioxidant capacity oil
}

\author{
Maria do Socorro M. Rufino ${ }^{\mathrm{a}, \mathrm{b}, 1}$, Jara Pérez-Jiménez ${ }^{\mathrm{b}, 2}$, Sara Arranz ${ }^{\mathrm{b}}$, Ricardo Elesbão Alves ${ }^{\mathrm{c}, *}$, \\ Edy S. de Brito ${ }^{c}$, Maria S.P. Oliveira ${ }^{d}$, Fulgencio Saura-Calixto ${ }^{b}$ \\ ${ }^{a}$ Federal Rural University of the Semi-Arid, BR 110, Km 47, Presidente Costa e Silva, 59625-900, Mossoró, RN, Brazil \\ ${ }^{\mathrm{b}}$ Department of Metabolism and Nutrition, Institute for Food Science and Technology and Nutrition (ICTAN-CSIC), Calle José Antonio Novais, 10, 28040 Madrid, Spain \\ c Embrapa Tropical Agroindustry, R. Dra. Sara Mesquita, 2270, Pici, 60511-110, Fortaleza, CE, Brazil \\ ' Embrapa Western Amazonia, Trav. Dr. Enéas Pinheiro s/nº, 66095-100, Belém, PA, Brazil
}

\section{A R T I C L E I N F O}

\section{Article history:}

Received 1 July 2010

Received in revised form 8 September 2010 Accepted 10 September 2010

\section{Keywords:}

Euterpe oleraceae

Polyphenols

Antioxidant dietary fiber

Oil

Antioxidant capacity

\begin{abstract}
A B S T R A C T
This article reports a study of the concentrations of dietary fiber (DF) and antioxidant capacity in fruits (pulp and oil) of a new açaí (Euterpe oleraceae) cultivar-'BRS-Pará', with a view to determine the possibility of using it as a source of antioxidants in functional foods or dietary supplements. Results show that 'BRS-Pará' açaí fruits has a high content of DF (71\% dry matter) and oil (20.82\%) as well as a high antioxidant capacity in both defatted matter and oil. 'BRS-Pará' Açaí fruits can be considered as an excellent source of antioxidant dietary fiber. Antioxidant capacity of açaí 'BRS-Pará' oil by DPPH assay was higher $\left(\mathrm{EC}_{50}=646.3 \mathrm{~g} / \mathrm{g}\right.$ DPPH$)$ than extra virgin olive oil $\left(\mathrm{EC}_{50}=2057.27 \mathrm{~g} / \mathrm{g} \mathrm{DPPH}\right)$. These features provide açaí 'BRS-Pará' fruits with considerable potential for nutritional and health applications.
\end{abstract}

(C) 2010 Elsevier Ltd. All rights reserved.

\section{Introduction}

Açaí (Euterpe oleraceae), also known as cabbage palm, is a tropical species which bears a dark purple, berry-like fruit, clustered into bunches. Its exportation to other non-tropical countries, to be used mainly in fruit juices, has increased during several years.

Recently, much attention has been paid to its antioxidant capacity and its possible role as a functional food or food ingredient (Coïsson, Travaglia, Piana, Capasso, \& Arlorio, 2005; Jensen et al., 2008; MertensTalcott et al., 2008; Pozo-Insfran, Percival, \& Talcott, 2006; Ribeiro et al., 2010; Schreckinger, Lotton, Lila, \& Mejia, 2010). The phytochemical and

Abbreviations: ABTS, 2,2'-Azino-bis(3-ethylbenzo-thiazoline-6-sulfonic acid); ADF, antioxidant dietary fiber; $A E$, antiradical efficiency $\left(A E=1 /\left(E_{50} t_{E C 50}\right)\right.$; $D F$, dietary fiber; $D P P H^{\bullet}, 2,2$-Diphenyl-1-picrylhydrazyl; $E C_{50}$, concentration of antioxidant needed to reduce the original amount of radical by $50 \%$; EPP, extractable polyphenols; FRAP, Ferric Reducing/Antioxidant Power; GAE, gallic acid equivalents; $I D F$, insoluble dietary fiber; NSP, nonstarch polysaccharides; ORAC, Oxygen Radical Absorbance Capacity; SDF, soluble dietary fiber; $t_{E C 50}$, time needed to reach the steady state to EC50 concentration; TPTZ, 2,4,6-Tris(2-pyridyl)-s-triazine; Trolox, 6-Hydroxy-2,5,7,8-tetramethylchroman2-carboxylic acid.

* Corresponding author. Tel.: +55 853391 7202; fax: + 558533917222.

E-mail address: elesbao@cnpat.embrapa.br (R.E. Alves).

1 Current address: Food Technology Department, Federal University of Ceara, Av. Mister Hall, 2977, Bloco 858, Pici, 60356-000, Fortaleza, CE, Brazil.

${ }^{2}$ Current address: Institute of Advanced Chemistry of Catalonia-CSIC, c/ Jordi Girona, 18-26, 08034 Barcelona, Spain. nutrient composition of açaí have been investigated (Rufino, Alves, Brito, Silveira, \& Moura, 2009; Rufino et al., 2010). Anthocyanins, proanthocyanidins, and other flavonoids were found to be the major phytochemicals in freeze-dried açaí (Schauss et al., 2006) and some works have dealt with the antioxidant capacity of açaí pulp (Souza et al., 2009; Rufino, Alves, Brito, Perez-Jimezes, \& Saura-Calixto, 2009; Rufino, Fernandes, Alves, \& Brito, 2009; Rufino et al, 2010;). However, since açaí is an oil-rich fruit, it may be necessary, when determining its antioxidant capacity, to study separately its oil and its defatted fraction to avoid interferences, as it has been suggested for similar fruits (Arranz, Pérez-Jiménez, \& SauraCalixto, 2008). This has not been carried out up to the moment.

Cereals are usually studied as main sources of dietary fiber (DF). Nevertheless, it is well-known that the DF from some fruits, that contains a higher proportion of soluble dietary fiber (SDF) and associated bioactive compounds than cereals, has properties related to gastrointestinal health and prevention of chronic diseases (Spiller, 2001). Antioxidant DF (ADF) is defined as a natural product that combines the beneficial effects of DF and natural antioxidants, such as polyphenol compounds (Saura-Calixto, 1998). On the one hand, ADF can be used as a dietary supplement to improve gastrointestinal health and to prevent cardiovascular diseases (Pérez-Jiménez, Serrano, et al., 2008), and on the other as an ingredient in seafood and meat products to prevent lipid oxidation (Sánchez-Alonso, Jiménez-Escrig, Saura-Calixto, \& Borderías, 2006).

Traditionally açaí grows on flooded areas. However, through a genetic breeding program based on phenotypic selection from its germplasm 
bank, Embrapa Western Amazonia (Belém, PA, Brazil) developed a cultivar-the 'BRS-Pará'-suitable for growing on stable land, as a result the production system of this plant has now been modified making it easier and more productive than the traditional system.

The aim of this work was to study the concentrations of DF and antioxidant capacity in açaí, 'BRS-Pará' with a view to determining the possibility of using it as a source of antioxidant in functional foods or dietary supplements. Due to its high oil content, antioxidant capacity was studied separately in the defatted pulp and in the oil, to avoid interferences. Finally, since the association of antioxidants with DF may produce specific physiological effects, the polyphenols and the antioxidant capacity associated to DF were also determined.

\section{Materials and methods}

\subsection{Chemicals}

Pepsin (2000 FIP-U/g), glucose, inositol and $N$-methylimidazole were obtained from Merck (Darmstadt, Germany). Amyloglucosidase (14 IU/mg) was from, Roche, Manheim, Germany. Pancreatin, $\alpha$ amylase (17.5 IU/mg), 2,2'-Azino-bis(3-ethylbenzo-thiazoline-6sulfonic acid) (ABTS), 6-hydroxy-2,5,7,8-tetramethylchroman-2carboxylic acid (Trolox), catechin, gallic acid, galacturonic acid, galactose and mannose were obtained from Sigma-Aldrich Química, S.A. (Madrid, Spain). 2,4,6-Tris(2-pyridyl)-s-triazine (TPTZ) was from Fluka Chemicals (Madrid, Spain). Dinitrosalicylic acid, 3,6'-dihydroxyspiro-[isobenzofuran-1-[3H],90[9H]-xanthen]-3-one (fluorescein) and iron III-chlorure-6-hydrate were from Panreac, Castellar del Vallés (Barcelona, Spain). All reagents used were of analytical grade.

\subsection{Samples}

Fruits of açaí 'BRS-Pará' were harvested at Embrapa Western Amazonia at Belém-PA, Brazil. After harvesting, the fruits were transported to the Postharvest Physiology and Technology Laboratory, at Embrapa Tropical Agroindustry, Fortaleza-CE, Brazil. Two kilograms of fruit were harvested in the second semester of 2007 at the commercial maturity stage (completely ripe). Samples were taken from 10 different trees and from different regions of them, to achieve a homogeneous sample. They were processed in a domestic blender (Walita, Brazil) to obtain a pulp and the seeds were discarded. Pulp was later divided in three sub-samples to carry out the different analysis and each one of them was freeze-dried (LH 4500, Terroni Fauvel, Brazil) and milled to a particle size of less than $0.5 \mathrm{~mm}$ in a centrifugal mill. The fact that these fruits were from the same genotype (clone) guaranteed a similarity in the chemical composition of them.

\subsection{Methods}

Previously the samples were deffated with petroleum ether at $60{ }^{\circ} \mathrm{C}$ on a Soxhlet apparatus, using two extraction cycles of $30 \mathrm{~min}$. Figs. 1 and 2 show a scheme of the treatments performed to the samples to determine DF and antioxidant capacity.

Determinations were performed in triplicate and reported on a dry matter. Results are expressed as mean values \pm standard deviation.

\subsubsection{Dietary fiber determination}

The DF was measured based on the procedure described by SauraCalixto, Garcia-Alonso, Goñi and Bravo (2000). This method combines enzymatic treatments and separation of digestible compounds by dialysis using physiological conditions (temperature and $\mathrm{pH}$ ), obtaining the fraction of food that is not digested (Fig. 1). Total DF was calculated as the sum of insoluble dietary fiber or IDF (constituted by nonstarch polysaccharides or NSP, Klason lignin, resistant protein, ash, extractable polyphenols, proanthocyanidins, and hydrolyzable tannins) and soluble dietary fiber or SDF (constituted by soluble nonstarch polysaccharides or NSP and extractable polyphenols).

Samples (300 mg) were incubated with pepsin $(0.2 \mathrm{~mL}$ of a $300 \mathrm{mg} / \mathrm{mL}$ solution in $0.08 \mathrm{M} \mathrm{HCl}-\mathrm{KCl}$ buffer, $\mathrm{pH} 1.5,40^{\circ} \mathrm{C}, 1 \mathrm{~h}$ ), pancreatin ( $1 \mathrm{~mL}$ of a $5 \mathrm{mg} / \mathrm{mL}$ solution in $0.1 \mathrm{M}$ phosphate buffer, $\mathrm{pH}$ $7.5,37^{\circ} \mathrm{C}, 6 \mathrm{~h}$ ) and $\alpha$-amylase $(1 \mathrm{~mL}$ of a $120 \mathrm{mg} / \mathrm{mL}$ solution in $0.1 \mathrm{M}$ Tris-maleate buffer, $\mathrm{pH} 6.9,37^{\circ} \mathrm{C}, 16 \mathrm{~h}$ ). Samples were centrifuged $(15 \mathrm{~min}, 3000 \times \mathrm{g}$ ) and supernatants removed. Residues were washed twice with $5 \mathrm{~mL}$ of distilled water, and all supernatants were combined. Each supernatant was incubated with $100 \mu \mathrm{L}$ of amyloglucosidase for $45 \mathrm{~min}$ at $60{ }^{\circ} \mathrm{C}$ before being transferred to dialysis tubes

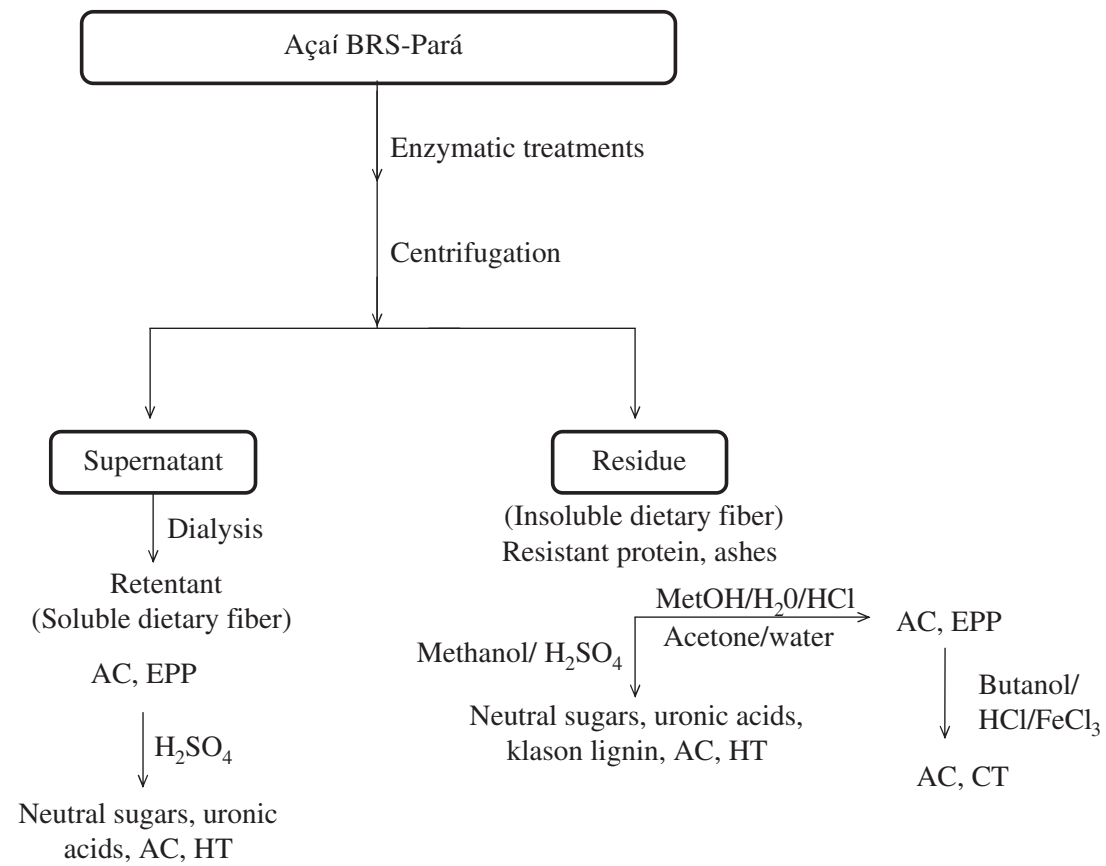

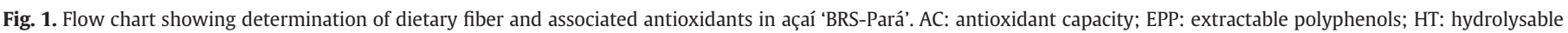
tannins; $\mathrm{CT}$ : condensed tannins. 


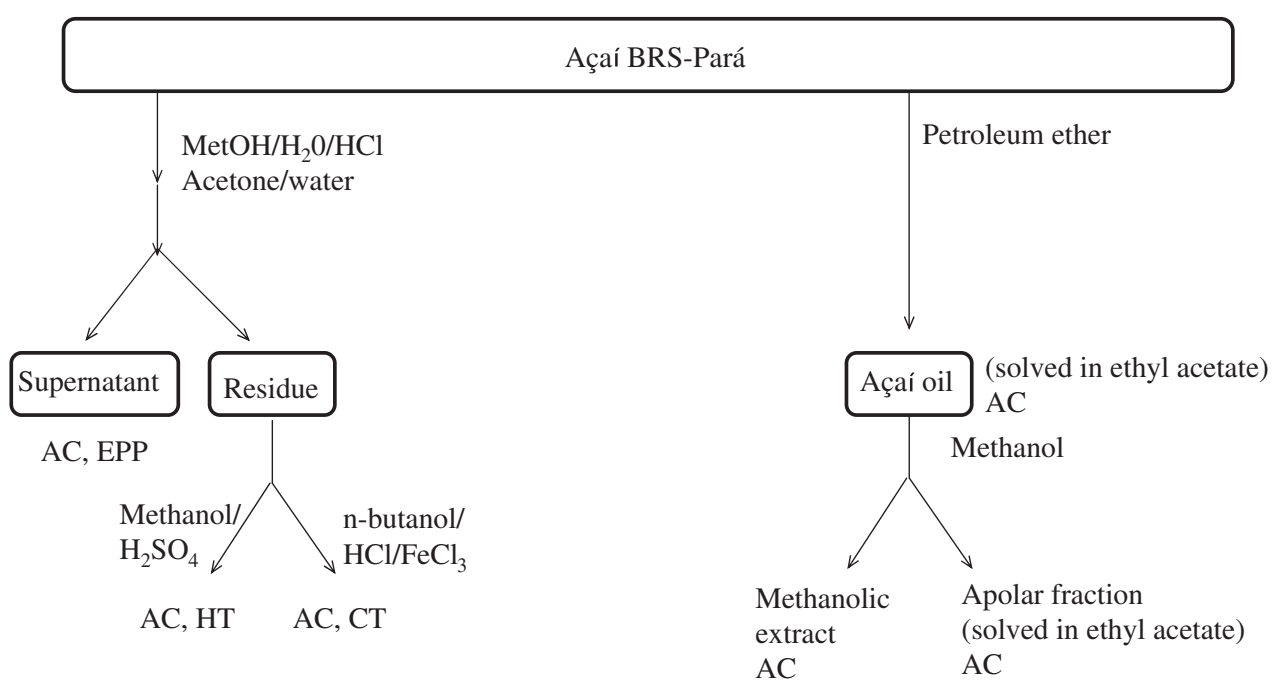

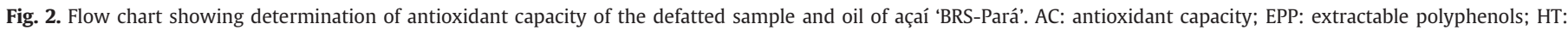
hydrolysable tannins; CT: condensed tannins.

(12,000-14,000 molecular weight cutoff, Visking dialysis tubing; Medicell International Ltd., London, U.K.) and dialyzed against water for $48 \mathrm{~h}$ at $25^{\circ} \mathrm{C}$ to eliminate digestible compounds. The products of all these treatments were therefore a residue after enzymatic treatments, corresponding to IDF, and a supernantant of enzymatic treatments later subjected to dialysis, corresponding to SDF.

In SDF, soluble NSP were hydrolyzed with $1 \mathrm{M}$ sulfuric acid at $100{ }^{\circ} \mathrm{C}$ for $90 \mathrm{~min}$ and measured as the sum of neutral sugars, determined by GC, and uronic acids, determined spectrophotometrically (Scott, 1979) using galacturonic acid as standard. Regarding GC, neutral sugars were derivatized to alditol acetates (Englyst, Wiggins \& Cummings, 1984) by a first treatment with $\mathrm{NH}_{4} \mathrm{OH}$, octan-2-ol and $\mathrm{NaBH} 4$ during $30 \mathrm{~min}$ at $40^{\circ} \mathrm{C}$, followed by a second treatment with methylimidazole and acetic anhydride during $15 \mathrm{~min}$ and a final addition of KOH. A Shimadzu GC-14A chromatograph (Shimadzu Co., Kyoto, Japan) fitted with a flame ionization detector and a SP-2330 capillary column $(30 \mathrm{~m} \times 0.32 \mathrm{~mm}$ i.d., catalog no. 2-4073, Supelco, Bellefonte, PA) were used. Analytical conditions were as follows: column temperature, $240{ }^{\circ} \mathrm{C}$ (isothermal); injector temperature, $270{ }^{\circ} \mathrm{C}$; detector temperature, $270{ }^{\circ} \mathrm{C}$; carrier gas, nitrogen. Inositol was used as internal standard. Finally, extractable polyphenols were also determined in SDF as described in the later part-see Section 2.3.2.3.

Regarding IDF, the residue was weighed to determine gravimetrically IDF content in the sample, and it was divided in three fractions to analyze its different constituents. A first fraction was used to determine insoluble NSP and Klason lignin (Southgate, 1969): after treatment with sulphuric acid $\left(12 \mathrm{M}, 20^{\circ} \mathrm{C}\right.$ for $3 \mathrm{~h}$; dilution to $1 \mathrm{M}$ and incubation for $2 \mathrm{~h}, 100^{\circ} \mathrm{C}$ ), insoluble NSP were determined as the sum of neutral sugars and uronic acids as described above for soluble NSP, and Klason lignin was determined gravimetrically. In the supernatant of this treatment hydrolyzable tannins content was also determinedas discussed after Section 2.3.2.3. A second fraction of the residue was used to determine in it resistant protein and ash-see 2.3.3. The third fraction was subjected to a first treatment to determine extractable polyphenols-see Section 2.3.2.1, followed by a second treatment to determine condensed tannins content-see Section 2.3.2.3.

\subsubsection{Antioxidant capacity and phenolic compounds determination}

2.3.2.1. Extraction of antioxidants. $0.5 \mathrm{~g}$ of either IDF of açaí (Fig. 1) or defatted açaí pulp (Fig. 2) was placed in a capped centrifuge tube;
$20 \mathrm{~mL}$ of acidic methanol/water (50:50, v/v; pH 2) was added and the tube was thoroughly shaken at room temperature for $1 \mathrm{~h}$. The tube was centrifuged at $2500 \times \mathrm{g}$ for $10 \mathrm{~min}$ and the supernatant recovered. Twenty milliliters of acetone/water (70:30, v/v) were added to the residue, and shaking and centrifugation repeated. Methanolic and acetonic extracts were combined and used to determine the antioxidant capacity associated with extractable antioxidants (Figs. 1 and 2). The residues of these extractions were subjected either to hydrolisis with $\mathrm{H}_{2} \mathrm{SO}_{4}$ to release hydrolyzable tannins (Figs. 1 and 2) or to treatment with n-butanol/ $\mathrm{HCl} / \mathrm{FeCl}_{3}$ to release anthocyanins from proanthocyanidins or condensed tannins (Figs. 1 and 2)-see conditions in Section 2.3.2.3. Antioxidant capacity was determined in both hydrolyzable tannins and condensed tannins.

Total antioxidant capacity was determined directly in vegetable oils, after diluting aliquots in ethyl acetate. To determine separately antioxidant capacity associated to polar and apolar compounds, $5 \mathrm{~mL}$ of oil were mixed with $5 \mathrm{~mL}$ of methanol. The mixture was vigorously stirred for $20 \mathrm{~min}$ and centrifuged at $2500 \times \mathrm{g}$ for $10 \mathrm{~min}$ and the supernatant was recovered. Another $5 \mathrm{~mL}$ were added and the same process was repeated. Antioxidant capacity was measured directly in the methanolic extract (that extracts polar compounds) and in the remaining oil (apolar fraction), after dilution with ethyl acetate (Espín, Soler-Rivas, \& Wichers, 2000).

\subsubsection{Antioxidant capacity methods}

2.3.2.2.1. $\mathrm{DPPH}$ (free-radical scavenging) assay. It was used the method described by Brand-Williams, Cuvelier, and Berset (1995), later modified by Sánchez-Moreno, Larrauri, and Saura-Calixto (1998), in order to determine kinetic parameters. After adjusting the blank with methanol, $0.1 \mathrm{~mL}$ of the sample was mixed with $3.9 \mathrm{~mL}$ of a $\mathrm{DPPH}^{*}$ methanolic solution $(60 \mu \mathrm{M})$. The absorbance at $515 \mathrm{~nm}$ was measured until the reaction reached the plateau. A calibration curve at that wavelength was made to calculate the remaining $\mathrm{DPPH}^{\circ}$. The parameter $\mathrm{EC}_{50}$, which reflects $50 \%$ depletion of $\mathrm{DPPH}^{*}$, was expressed in terms of grams of açaí equivalent per gram of $\mathrm{DPPH}^{\circ}$ in the reaction medium. The time taken to reach the steady state at $\mathrm{EC}_{50}$ $\left(t_{\mathrm{EC} 50}\right)$ and the antiradical efficiency $\left(\mathrm{AE}=1 / \mathrm{EC}_{50} t_{\mathrm{EC} 50}\right)$ were also determined.

2.3.2.2.2. ABTS assay at a fixed end-point. ABTS radical cation $\left(\mathrm{ABTS}^{\bullet+}\right)$ was produced by reacting $7 \mathrm{mM}$ ABTS stock solution with $2.45 \mathrm{mM}$ potassium persulfate and allowing the mixture to stand in the dark at room temperature for $12-16 \mathrm{~h}$ before use. The $\mathrm{ABTS}^{*+}$ solution was 
diluted with methanol to an absorbance of $0.70 \pm 0.02$ at $658 \mathrm{~nm}$. After the addition of $100 \mu \mathrm{L}$ of sample or Trolox standard to $3.9 \mathrm{~mL}$ of diluted $\mathrm{ABTS}^{++}$solution, absorbance readings were taken every $20 \mathrm{~s}$, using a Beckman DU-640 (Beckman Instruments Inc. Fullerton, CA, USA) spectrophotometer. The reaction was monitored during $6 \mathrm{~min}$. The percentage inhibition of absorbance versus time was plotted, and the area below the curve (0-6 min) was calculated (Re et al., 1999). Methanolic solutions of known Trolox concentrations were used for calibration.

2.3.2.2.3. ABTS assay expressed kinetically. The ABTS radical cation is generated as described for the ABTS assay at a fixed end-point. A recent procedure described modified the original method so as to determine kinetic parameters. An aliquot of the sample extract $(0.1 \mathrm{~mL})$ is added to $3.9 \mathrm{~mL}$ of $\mathrm{ABTS}^{*+}(0.044 \mathrm{~g} / \mathrm{L})$ in methanol which was prepared daily. Absorbances at $658 \mathrm{~nm}$ are measured at different time intervals on a spectrophotometer until the reaction reaches a plateau. The ABTS ${ }^{+}$ concentration in the reaction medium is calculated by plotting concentration vs. absorbance. $\mathrm{EC}_{50}, \mathrm{t}_{\mathrm{EC} 50}$ and $\mathrm{AE}$ are calculated as in the DPPH assay (Pérez-Jiménez \& Saura-Calixto, 2008).

2.3.2.2.4. FRAP (ferric reducing antioxidant power) assay. $900 \mu \mathrm{L}$ of FRAP reagent (80\% acetate buffer, 10\% TPTZ $10 \mathrm{mM}$ and 10\% iron IIIchlorure-6-hydrate $20 \mathrm{mM}$ ), freshly prepared and warmed at $37^{\circ} \mathrm{C}$, was mixed with $90 \mu \mathrm{L}$ of distilled water and either $30 \mu \mathrm{L}$ of test sample or standard or appropriate reagent blank. Reading at the absorption maximum (595 nm) was taken every $15 \mathrm{~s}$, using a spectrophotometer. The readings at $30 \mathrm{~min}$ were selected for calculation of FRAP values (Benzie \& Strain, 1996; Pulido, Bravo, \& Saura-Calixto, 2000). Solutions of known Trolox concentrations were used for calibration.

2.3.2.2.5. ORAC (oxygen radical absorbance capacity) assay. Sample/ blank is mixed with PBS buffer, AAPH and fluorescein. Fluorescence was recorded until it reached zero (excitation wavelength $493 \mathrm{~nm}$, emission wavelength $515 \mathrm{~nm}$ ) in a fluorescence spectrophotometer Perkin-Elmer LS 55 at $37^{\circ} \mathrm{C}$ (Ou, Hampsch-Woodill, \& Prior, 2001). Results were calculated using the differences of areas under the fluorescein decay curve between the blank and the sample and were expressed as Trolox equivalents.

2.3.2.3. Antioxidant compounds content. The content of extractable polyphenols (EPP) was determined in SDF, extracts of IDF (Fig. 1) and in extracts of the defatted pulp (Fig. 2) according to the FolinCiocalteu method (Singleton, Orthofer, \& Lamuela-Raventós, 1999). Test sample $(0.5 \mathrm{~mL})$ was mixed with $1 \mathrm{~mL}$ of Folin-Ciocalteu reagent and swirled. After $3 \mathrm{~min}, 10 \mathrm{~mL}$ of sodium carbonate solution $(75 \mathrm{~g} / \mathrm{L})$ was added and mixed. Additional distilled water was mixed thoroughly by inverting the tubes several times. After $1 \mathrm{~h}$, the absorbance at $750 \mathrm{~nm}$ was recorded. The results were expressed as $\mathrm{g}$ of gallic acid equivalents (GAE)/100 $\mathrm{g}$.

Proanthocyanidins (condensed tannins) not extracted by the previous aqueous-organic procedure were measured at $555 \mathrm{~nm}$ after hydrolysis with n-butanol $/ \mathrm{HCl} / \mathrm{FeCl}_{3}\left(3 \mathrm{~h}, 100{ }^{\circ} \mathrm{C}\right.$ ) (Reed, McDowell, Van Soest, \& Horvath, 1982) either in the residue of the extraction of IDF (Fig. 1) or in the residue of the extraction of açai defatted pulp (Fig. 2). Results were compared with carob pod (Ceratonia siliqua L.) proanthocyanidin standard (Nestlé, Ltd., Vers-Chez-les Blancs, Switzerland).

Hydrolyzable tannins were measured according to a method previously described (Hartzfeld, Forkner, Hunter, \& Hagerman, 2002) by hydrolysis with methanol and sulfuric acid for $20 \mathrm{~h}$ at $85^{\circ} \mathrm{C}$. They were determined in the hydrolysates of IDF (Fig. 1) and in the residues of the extraction of açaí defatted pulp (Fig. 2). Concentration was estimated by the Folin-Ciocalteu method (Singleton et al., 1999) and expressed as g GAE/100 g.

\subsubsection{Proximate composition determination}

Protein was determined using an automated nitrogen analyser FP2000®; Dumas Leco Corp. Lipids were determined using a Soxhlet System HT extractor with petroleum ether, and fatty acid composition by GC, after derivatization to methyl sters (Gómez-Cortés et al., 2008).
Ash content was gravimetrically determined by incinerating samples in an electric muffle furnace at $550{ }^{\circ} \mathrm{C}$ for $16 \mathrm{~h}$.

\section{Results and discussion}

\subsection{Proximate composition}

Proximate composition values are presented in Table 1 . The most significant aspect of açaí 'BRS-Para' is its high DF content (70\% dry matter), the bulk of it being insoluble DF. Açaí DF content, as in other tropical fruits, is much higher than in common fruits like apples, oranges or bananas in which it ranges from 17 to $36 \%$ (Saura-Calixto et al., 2000). Moreover, açaí contains comparable levels of DF to other products described as rich in DF, such as pineapple shell or grape pomace (Larrauri, Rupérez, \& Saura-Calixto, 1997; Pérez-Jiménez, Arranz, et al., 2008), and higher than other tropical fruits like guava or papaya (Jiménez-Escrig, Rincón, Pulido, \& Saura-Calixto, 2001; Mahattanatawee et al., 2006).

Table 2 shows the composition of açaí 'BRS-Pará' DF, including neutral sugars (determined individually), uronic acids, Klason lignin, resistant protein, and ash. Glucose and galactose were the main neutral sugars in SDF, while arabinose and xylose were the major monosaccharides in IDF indicating the presence of arabinoxylans.

These portions of non digestible carbohydrates reach the colon where they are potentially fermentable by colonic microbiota. Some of the metabolites generated during colonic fermentation of carbohydrates, as short chain fatty acids (especially butyrate), were described as beneficial for intestinal health (Wong, Souza, Kendall, Emam, \& Jenkins, 2006).

Açaí also has high oil content (Table 1). Analysis of fatty acids (Table 3 ) showed that this fruit is a source of fatty acids of potential nutritional interest; containing almost as much oleic acid as olive oil, which contains $70 \%$ oleic acid on average, and more than other oil rich sources such as soy, corn and sunflower. This is in line with results reported by other authors on açaí from the Amazon estuary (Schauss et al., 2006).

Açaí also possesses a high phenolic content that presumably contributes to its antioxidant capacity, as it is discussed in the later part. Finally, the protein, soluble sugars and mineral content agreed with other reported data (Menezes, Torres, \& Srur, 2008).

\subsection{Polyphenols and antioxidant capacity}

The antioxidant capacity of any food sample comes from the combined synergic action of a mixture of compounds, including phenolics, carotenoids, vitamins $\mathrm{C}$ and $\mathrm{E}$, etc. Except for certain fruits such as acerola (Alves, Chitarra, \& Chitarra, 1995), in which vitamin C is one of the main component, in fruits like açaí which contain relatively little of this vitamin, polyphenols are the main contributors to antioxidant capacity.

Table 1

Proximate composition of Açaí ‘BRS-Pará' fruit pulp.

\begin{tabular}{lc}
\hline Component & $\mathrm{g} / 100 \mathrm{~g} \mathrm{dm}^{\mathrm{a}}$ \\
\hline Protein & $6.27 \pm 0.31$ \\
Ashes & $1.99 \pm 0.17$ \\
Soluble sugars & $7.93 \pm 2.11$ \\
Total lipids & $20.82 \pm 1.60$ \\
Soluble dietary fiber & $2.75 \pm 0.16^{\mathrm{b}}$ \\
Insoluble dietary fiber & $68.49 \pm 1.21^{\mathrm{c}}$ \\
Total dietary fiber & $71.22 \pm 1.22$ \\
Polyphenols & \\
$\quad$ Extractable polyphenols & $1.50 \pm 0.05$ \\
$\quad$ Hydrolyzable tannins & $1.59 \pm 0.18$ \\
Condensed tannins & $1.24 \pm 0.14$
\end{tabular}

$\mathrm{dm}$ : dry matter. Moisture: $85.7 \%$.

a Mean value \pm standard deviation, $\mathrm{n}=3$.

b Determined as non-starchy polysaccharides + associated polyphenols.

Determined gravimetrically.

d A fraction of them is included in dietary fiber. 
Table 2

Composition of dietary fiber of Açaí ‘BRS-Pará' pulp (\% dmª $)$.

\begin{tabular}{llll}
\hline Component & $\begin{array}{l}\text { Soluble dietary } \\
\text { fiber }\end{array}$ & $\begin{array}{l}\text { Insoluble dietary } \\
\text { fiber }\end{array}$ & $\begin{array}{l}\text { Total dietary } \\
\text { fiber }\end{array}$ \\
\hline Total neutral sugars & $0.65 \pm 0.04$ & $11.90 \pm 0.07$ & $12.55 \pm 0.10$ \\
Arabinose & $0.10 \pm 0.04$ & $0.65 \pm 0.02$ & $0.75 \pm 0.04$ \\
Fucose & n.d. & $0.09 \pm 0.01$ & $0.09 \pm 0.01$ \\
Galactose & $0.16 \pm 0.04$ & $0.29 \pm 0.01$ & $0.45 \pm 0.04$ \\
Glucose & $0.39 \pm 0.03$ & $0.25 \pm 0.01$ & $0.64 \pm 0.03$ \\
Mannose & $0.003 \pm 0.0001$ & $0.03 \pm 0.004$ & $0.03 \pm 0.005$ \\
Rhamnose & n.d. & n.d. & n.d. \\
Xylose & n.d. & $10.59 \pm 0.23$ & $10.59 \pm 0.23$ \\
Uronic acids & $0.98 \pm 0.08$ & $15.96 \pm 0.48$ & $16.92 \pm 0.70$ \\
Klason lignin & - & $39.27 \pm 0.02$ & $39.27 \pm 0.02$ \\
Resistant protein & - & $5.60 \pm 0.20$ & $5.60 \pm 0.20$ \\
Ash & - & $1.02 \pm 0.30$ & $1.02 \pm 0.30$ \\
Polyphenols & $1.12 \pm 0.13$ & $2.93 \pm 0.11$ & $4.05 \pm 0.17$ \\
Dietary fiber & $2.75 \pm 0.16$ & $76.68 \pm 0.80$ & $79.43 \pm 0.81$ \\
\hline
\end{tabular}

dm: dry matter.

${ }^{\text {a }}$ Mean value \pm standard deviation, $\mathrm{n}=3$. n.d. non detected.

Polyphenol content determined in the pulp aqueous-organic extracts can be seen in Table 4 . The values are similar to those reported by other authors (Schauss et al., 2006). The main phenolic compounds reported in açaí pulp have been cyanidin 3-O-glucoside, a cyanidin 3-O-rutinoside, homoorientin, orientin, and isovitexin (Gallori, Bilia, Bergonzi, Barbosa, \& Vincieri, 2004), and in the related fruit jussara (Euterpe edulis) cyanidin 3-O-glucoside and cyanidin 3O-rutinoside (Brito et al., 2007).

Total polyphenols present in the residue of these extractions that is, hydrolyzable and condensed tannins were determined, giving values of 1.59 and $1.24 \mathrm{~g} / 100 \mathrm{~g}$ dry weight, respectively, being therefore as abundant as extractable polyphenols. Although nonbioavailable in the small intestine, these non extractable polyphenols reach the colon intact and there becomes fermentable substrates for colonic bacterias. The fermentation of these compounds release antioxidant metabolites that may improve the colonic status and yield some absorbable metabolites (Cerdá, Periago, Espín, \& TomásBarberán, 2005; Gonthier et al., 2003).

The antioxidant capacity associated with these non-extractable phenolic compounds in açaí had not been previously determined. Regarding the oil, it was found only one reference in which the antioxidant capacity of açaí oil was measured by ORAC assay (Pacheco-Palencia, Mertens-Talcott, \& Talcott, 2008). Therefore, another aim of this work was to determine the total antioxidant capacity of this fruit. In order to perform these determinations, it was necessary to defat the açaí since its high oil content could interfere in the measurement of this parameter (Arranz et al., 2008).

\subsubsection{Antioxidant capacity of defatted pulp}

Antioxidant capacity associated with phenolic compounds was determined by FRAP, ABTS, DPPH and ORAC (Table 4)-the different pros and cons linked to each one of the available antioxidant capacity

Table 3

Fatty acid composition and oil of Açaí ‘BRS-Pará' fruit pulp.

\begin{tabular}{lcc}
\hline Component & Fatty acid $(\mathrm{g} / 100 \mathrm{~g} \mathrm{dm})$ & Oil (\%) \\
\hline Saturated & 6.9 & 26.7 \\
C16:0 & 5.3 & 25.3 \\
C18:0 & 1.6 & 1.4 \\
Monounsaturated & 13.0 & 62.3 \\
Cis-9 C16:1 & 1.1 & 5.4 \\
Cis-9 C18:1 & 10.9 & 52.1 \\
Cis-11 C18:1 & 1.0 & 4.8 \\
Polyunsaturated & 2.3 & 11.1 \\
Cis-9, cis-12 C18:2 & 2.2 & 10.6 \\
Cis-9, cis-12, cis-15 C18:3 & 0.1 & 0.5 \\
\hline
\end{tabular}

dm: dry matter.
Table 4

Polyphenols and antioxidant capacity in aqueous-organic extracts and its residues of defatted Açaí ‘BRS-Pará' fruit pulp. ${ }^{\text {' }}$

\begin{tabular}{|c|c|c|c|}
\hline Analysis & $\begin{array}{l}\text { Extractable } \\
\text { polyphenols }\end{array}$ & $\begin{array}{l}\text { Hydrolyzable } \\
\text { tannins }\end{array}$ & $\begin{array}{l}\text { Condensed } \\
\text { tannins }\end{array}$ \\
\hline Polyphenols (mg/g dm) & $15.0 \pm 0.5$ & $15.9 \pm 1.8$ & $12.4 \pm 1.4$ \\
\hline FRAP ( $\mu$ mol Trolox/g dm) & $128.44 \pm 8.51$ & $109.87 \pm 5.19$ & n.d. \\
\hline ORAC ( $\mu \mathrm{mol}$ Trolox/g dm) & $379.97 \pm 11.96$ & $1514.46 \pm 20.20$ & n.d. \\
\hline $\begin{array}{l}\text { ABTS at a fixed } \\
\text { end-point ( } \mu \text { mol Trolox/g dm) }\end{array}$ & $55.79 \pm 1.12$ & $20.73 \pm 0.04$ & $24.62 \pm 4.52$ \\
\hline \multicolumn{4}{|l|}{ ABTS expressed kinetically } \\
\hline $\mathrm{EC}_{50}(\mathrm{~g} \mathrm{dm} / \mathrm{g} \mathrm{ABTS})$ & $1.20 \pm 0.04$ & $13.61 \pm 0.15$ & $14.36 \pm 0.59$ \\
\hline $\mathrm{t}_{\mathrm{EC} 50}(\mathrm{~min})$ & $24.23 \pm 1.58$ & $25.20 \pm 1.16$ & $51.92 \pm 7.03$ \\
\hline $\mathrm{AE}^{\mathrm{b}}$ & 0.034 & 0.003 & 0.001 \\
\hline \multicolumn{4}{|l|}{ DPPH } \\
\hline $\mathrm{EC}_{50}(\mathrm{~g} \mathrm{dm} / \mathrm{g} \mathrm{DPPH})$ & $10.20 \pm 0.10$ & $4.92 \pm 0.10$ & n.d. \\
\hline $\mathrm{t}_{\mathrm{EC} 50}(\min )$ & $41.43 \pm 0.90$ & $11.00 \pm 0.69$ & n.d. \\
\hline $\mathrm{AE}^{\mathrm{b}}$ & 0.002 & 0.018 & n.d. \\
\hline
\end{tabular}

dm: dry matter. n.d. non determined. All values are expressed per gram of dry whole açaí.

a Mean value \pm standard deviation, $\mathrm{n}=3$

b Antiradical efficiency, $\mathrm{AE}=1 /\left(\mathrm{EC}_{50} t_{\mathrm{EC} 50}\right)$.

assays make necessary the use of at least two of these techniques (PérezJiménez, Arranz, et al., 2008). The aqueous-organic extracts obtained from defatted açaí, showed high antioxidant capacity, mainly due to extractable polyphenols, as well as the residues of açaí defatted pulp, where hydrolyzable and condensed tannins are the main contributors to antioxidant capacity. In the case of condensed tannins, only ABTS was a suitable procedure to determine their antioxidant capacity, since the other methods are not suitable to be performed in the butanol media needed the release of anthocyanins from proanthocyanidins.

Regarding kinetic measurements, extractable polyphenols were better radical scavengers than hydrolyzable tannins when ABTS assay was used (lower $\mathrm{EC}_{50}$ ), but worse radical scavengers towards DPPH assay $\left(E_{50}\right.$ of $4.92 \mathrm{~g} / \mathrm{g}$ for hydrolyzable tannins vs 10.20 for extractable polyphenols), indicating different mechanisms of reactions in these two assays (Huang, Ou, \& Prior, 2005). Fig. 3 shows the kinetic behaviour of açaí extracts $v s \mathrm{DPPH}^{\bullet}$.

\subsubsection{Antioxidant capacity of the oil}

Açaí 'BRS-Pará' oil antioxidant capacity results are shown in Table 5. Only total oil and apolar fraction values can be directly compared, since both were measured using ethyl acetate as solvent, while the polar fraction measurements were performed in methanol. The $\mathrm{EC}_{50}$ of the apolar fraction $(536.5 \mathrm{~g} / \mathrm{g}$ ) was higher than that of total oil (646.3) indicating a higher antioxidant capacity; therefore, it seems that most antioxidants in açaí oil are of an apolar nature, and the extraction of this fraction works as a mechanism to concentrate antioxidants.

We compared these values with extra virgin olive oil as a model of a lipophilic antioxidant-rich sample (Arranz et al., 2008), since oil extraction and antioxidant capacity measurements were equivalent in both studies. The $\mathrm{EC}_{50}$ of total oil was lower in the açaí oil than in the extra virgin olive oil (646.30 g/g DPPH vs. $2057.27 \mathrm{~g} / \mathrm{g}$ DPPH) indicating higher antioxidant capacity in the former. In contrast, the antiradical efficiency $(\mathrm{AE})$ of extra virgin olive oil was higher, because the time required for açaí oil to achieve the $\mathrm{EC}_{50}$ was longer than that required for the extra virgin olive oil. For the apolar fraction, again açaí oil had a lower $\mathrm{EC}_{50}$ than olive oil (536.53 g oil/g DPPH vs. $1210.96 \mathrm{~g}$ oil/g DPPH) and consequently higher antioxidant capacity to capture DPPH radical. Açaí and olive oil apolar fractions showed similar results for $t_{\mathrm{EC} 50}$. However, regarding polar fraction, olive oil exhibited a much higher antioxidant capacity $\left(\mathrm{EC}_{50}\right.$ of $10.2 \mathrm{~g} / \mathrm{g}$ ) than açaí oil $\left(\mathrm{EC}_{50}\right.$ of $1249.9 \mathrm{~g} / \mathrm{g})$.

Therefore, açaí oil appears as a new source of lipophilic antioxidants, with an antioxidant activity similar to olive oil, known by its high antioxidant compounds content. 


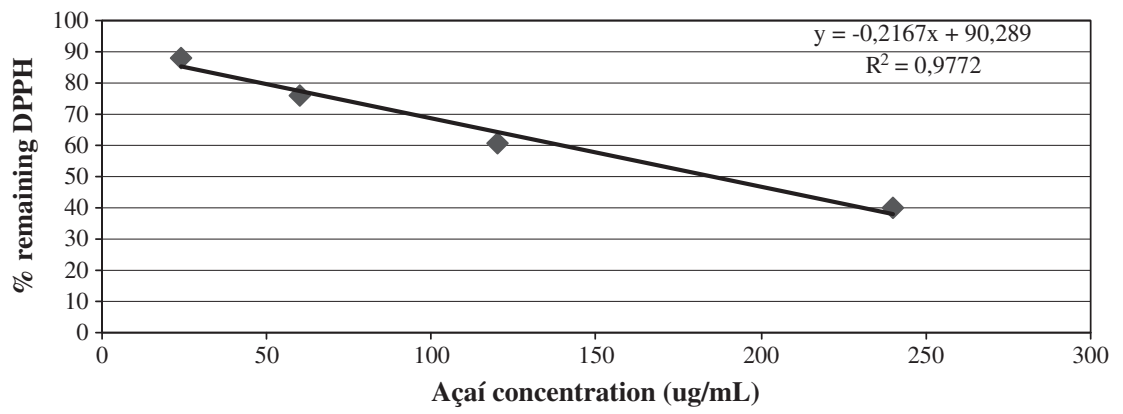

Fig. 3. Percentage of remaining DPPH ${ }^{\bullet} v s$ concentration of açaí in the DPPH assay.

3.2.3. Polyphenols and antioxidant capacity associated with dietary fiber

DF, measured as indigestible fraction (Saura-Calixto et al., 2000), is composed of two fractions: a soluble fraction (supernatant from enzymatic digestion) and an insoluble fraction (residue from enzymatic digestion). Antioxidant capacity and phenolic compounds associated with DF were determined in both fractions (Table 6).

The SDF contained associated (in an aqueous buffer) extractable polyphenols, while the IDF contained associated (in an aqueous organic solvent) extractable polyphenols, hydrolyzable tannins and condensed tannins. These constitute an important fraction of the polyphenols present in açaí pulp (Table 1), that is, most of them are associated with DF.

Although the values in Table 6 cannot be directly compared with those in Table 4, since the extraction methods were different (aqueous-organic vs enzymatic extraction), it can be seen that açaí DF exhibits considerable associated antioxidant capacity. For example, the ABTS value of condensed tannins in the IDF was $20.51 \pm 0.13 \mu \mathrm{mol}$ Trolox/g dm, while hydrolyzable tannins in IDF gave an ORAC value of $155.61 \pm 8.40 \mu \mathrm{mol}$ Trolox $/ \mathrm{g} \mathrm{dm}$. For comparative purposes, the antioxidant capacity associated with DF in a mixture of the fruits consumed in the Spanish diet has been calculated to be $2 \mu \mathrm{mol}$ Trolox/ g by ABTS assay (Serrano, Goñi, \& Saura-Calixto, 2007). Moreover, the antioxidant capacity of açaí DF is of nutritional significance, since these antioxidant compounds are thought to reach the colon intact in which they can produce a variety of beneficial effects.

In summary, antioxidant capacity and dietary fiber were determined in the fruit pulp of açaí 'BRS-Pará'. Pulp contains polyphenols with high antioxidant capacity, most of them being associated with DF. Its oil has higher antioxidant capacity than olive oil and a comparable fatty acid profile. The high DF content of açaí pulp and its associated polyphenols make this fruit a suitable source of antioxidant DF which may be used as a food ingredient to prevent lipid oxidation

Table 5

Antioxidant capacity of açaí 'BRS-Pará' fruit pulp oil and extra virgin olive oil (DPPH method) a .

\begin{tabular}{clll}
\hline & $\begin{array}{l}\text { Total antioxidant } \\
\text { capacity }^{\mathrm{b}}\end{array}$ & Polar fraction $^{\mathrm{c}}$ & $\begin{array}{l}\text { Apolar } \\
\text { fraction }^{\mathrm{d}}\end{array}$ \\
\hline Açaí BRS Pará oil & & & \\
$\mathrm{EC}_{50}$ (g oil/g DPPH) & $646.30 \pm 38.40$ & $1249.97 \pm 32.39$ & $536.53 \pm 11.78$ \\
$\mathrm{t}_{\mathrm{EC50}}(\mathrm{min})$ & $35.69 \pm 1.80$ & $17.87 \pm 0.33$ & $37.25 \pm 3.75$ \\
$\mathrm{AE}^{\mathrm{e}}$ & $0.4 \times 10^{-4}$ & $0.4 \times 10^{-4}$ & $1.0 \times 10^{-4}$ \\
Extra virgin olive oil $^{\mathrm{f}}$ & & & \\
$\mathrm{EC}_{50}$ (g oil/g DPPH) & $2057.27 \pm 75.56$ & $10.25 \pm 0.21$ & $1210.96 \pm 44.09$ \\
$\mathrm{t}_{\mathrm{EC50}}$ (min) & $4.86 \pm 0.05$ & $43.92 \pm 0.86$ & $35.31 \pm 1.65$ \\
$\mathrm{AE}^{\mathrm{e}}$ & $1 \times 10^{-4}$ & $2.2 \times 10^{-4}$ & 0 \\
\hline
\end{tabular}

a Mean value \pm standard deviation, $\mathrm{n}=3$.

b Determined in oil solved in ethyl acetate.

c Antioxidant capacity determined in methanolic extract.

d Antioxidant capacity determined in the remaining oil after methanolic extraction.

e Antiradical Efficiency, $\mathrm{AE}=1 /\left(\mathrm{EC}_{50} t_{\mathrm{EC} 50}\right)$.

${ }^{f}$ Arranz et al., 2008. in seafood and meat products, as well as in dietary supplements. These data suggest that açaí could have considerable potential for nutritional and health purposes.

\section{Authors' responsibilities}

The authors' responsibilities were as follows-F.S-C. and R.E.A., planned and monitored the work; M.S.M.R., J.P-J. and S.A., conducted the experimental work; M.S.P.O., provided the samples to carry out the work and contributed to their preparation; M.S.M.R., J.P-J. and R.E. A., wrote the first draft of the manuscript; and all authors contributed to writing the manuscript and approved the final version. None of the authors had a personal or financial conflict of interest.

\section{Acknowledgements}

Authors gratefully acknowledge financial support from the CAPES, ICTAN-CSIC, EMBRAPA, UFERSA and European Union (INCO-CT-2005015279). Dr. Miguel Ángel de la Fuente (Department of Dairy Products Science and Technology, ICTAN-CSIC) is acknowledged for his assistance in fatty acids profile analysis.

Table 6

Polyphenols and antioxidant capacity associated to dietary fiber of Açaí 'BRS-Pará' fruit pulp. $^{\text {a }}$

\begin{tabular}{|c|c|c|c|c|}
\hline \multirow[t]{2}{*}{ Analysis } & \multirow{2}{*}{$\begin{array}{l}\begin{array}{l}\text { Soluble dietary } \\
\text { fiber }\end{array} \\
\text { Extractable } \\
\text { polyphenols }\end{array}$} & \multicolumn{3}{|c|}{$\begin{array}{c}\text { Insoluble dietary } \\
\text { fiber }\end{array}$} \\
\hline & & $\begin{array}{l}\text { Extractable } \\
\text { polyphenols }\end{array}$ & $\begin{array}{l}\text { Hydrolyzable } \\
\text { tannins }\end{array}$ & $\begin{array}{l}\text { Condensed } \\
\text { tannins }\end{array}$ \\
\hline $\begin{array}{l}\text { Polyphenols } \\
\text { (mg/g dm) }\end{array}$ & $11.2 \pm 1.3$ & $4.2 \pm 0.2$ & $5.7 \pm 0.5$ & $19.4 \pm 1.0$ \\
\hline $\begin{array}{l}\text { FRAP } \\
\qquad(\mu \mathrm{mol} \text { Trolox/g dm })\end{array}$ & $46.82 \pm 4.65$ & $11.91 \pm 0.92$ & $11.64 \pm 0.84$ & n.d. \\
\hline $\begin{array}{l}\text { ORAC } \\
\qquad(\mu \mathrm{mol} \text { Trolox/g dm })\end{array}$ & $603.03 \pm 9.18$ & $53.72 \pm 6.65$ & $155.61 \pm 8.40$ & n.d. \\
\hline $\begin{array}{l}\text { ABTS at a fixed } \\
\text { end-point } \\
(\mu \mathrm{mol} \text { Trolox } / \mathrm{g} \mathrm{dm})\end{array}$ & $78.16 \pm 0.49$ & $3.96 \pm 0.22$ & n.d. & $\begin{array}{l}20.51 \\
\pm 0.13\end{array}$ \\
\hline \multicolumn{5}{|l|}{$\begin{array}{l}\text { ABTS expressed } \\
\text { kinetically }\end{array}$} \\
\hline $\begin{array}{l}\mathrm{EC}_{50} \\
(\mathrm{~g} \mathrm{dm} / \mathrm{g} \mathrm{ABTS})\end{array}$ & $8.95 \pm 0.04$ & $67.58 \pm 2.11$ & n.d. & $\begin{array}{l}14.41 \\
\pm 0.06\end{array}$ \\
\hline$t_{\mathrm{EC} 50}(\min )$ & $10.00 \pm 0.80$ & $20.47 \pm 2.04$ & n.d. & $\begin{array}{l}26.87 \\
\pm 0.49\end{array}$ \\
\hline$A E^{b}$ & 0.011 & 0.001 & n.d. & 0.002 \\
\hline \multicolumn{5}{|l|}{ DPPH } \\
\hline $\begin{array}{l}\mathrm{EC}_{50} \\
(\mathrm{~g} \mathrm{dm} / \mathrm{g} \mathrm{DPPH})\end{array}$ & $39.43 \pm 0.10$ & $119.20 \pm 5.42$ & $47.31 \pm 1.16$ & n.d. \\
\hline$t_{\mathrm{EC} 50}(\min )$ & $23.11 \pm 0.06$ & $31.22 \pm 0.58$ & $7.99 \pm 0.92$ & n.d. \\
\hline $\mathrm{AE}^{\mathrm{b}}$ & 0.001 & 0.0003 & 0.003 & n.d. \\
\hline
\end{tabular}

a Mean value \pm standard deviation, $\mathrm{n}=3$. d. m. dry matter. n.d. non determined.

b Antiradical Efficiency, $\mathrm{AE}=1 /\left(\mathrm{EC}_{50} t_{\mathrm{EC} 50}\right)$. 


\section{References}

Alves, R. E., Chitarra, A. B., \& Chitarra, M. I. F. (1995). Postharvest physiology of Acerola (Malpighia emarginata D.C.) fruits: Maturation changes, respiratory activity and refrigerated storage at ambient and modified atmospheres. Acta Horticulturae, 370, $223-230$.

Arranz, S., Pérez-Jiménez, J., \& Saura-Calixto, F. (2008). Antioxidant capacity of walnut (Juglans regia L.): Contribution of oil and defatted matter. European Food Research and Technology, 227, 425-431.

Benzie, I. F. F., \& Strain, J. J. (1996). The ferric reducing ability of plasma (FRAP) as a measure of antioxidant power: The FRAP assay. Analytical Biochemistry, 239, $70-76$.

Brand-Williams, W., Cuvelier, M. E., \& Berset, C. (1995). Use of a free radical method to evaluate antioxidant activity. Lebensmittel Wissenchaft und Technologie, 28, 25-30.

Brito, E. S., Araújo, M. C. P., Alves, R. E., Carkeet, C., Clevidence, B. A., \& Novotny, J. A. (2007). Anthocyanins present in selected tropical fruits: Acerola, jambolão, jussara, and guajiru. Journal of Agricultural and Food Chemistry, 55, 9389-9394.

Cerdá, B., Periago, P., Espín, J. C., \& Tomás-Barberán, F. A. (2005). Metabolism of antioxidant and chemopreventive ellagitannins from strawberries, raspberries, walnuts, and oak-aged wine in humans: Identification of biomarkers and individual variability. Journal of Agricultural and Food Chemistry, 53, 227-235.

Coïsson, J. D., Travaglia, F., Piana, G., Capasso, M., \& Arlorio, M. (2005). Euterpe oleracea juice as a functional pigment for yogurt. Food Research International, 38, 893-897.

Englyst, H. H., Wiggins, H. S., \& Cummings, J. H. (1984). Determination of the non-starch polysaccharides in plant foods by gas liquid chromatography of constituents sugars al alditol acetates. The Analyst, 109, 937-942.

Espín, J. C., Soler-Rivas, C., \& Wichers, H. J. (2000). Characterization of the total free radical scavenger capacity of vegetable oils and oil fractions using 2, 2-diphenyl-1picrylhydrazyl radical. Journal of Agricultural and Food Chemistry, 48, 648-656.

Gallori, S., Bilia, A. R., Bergonzi, M. C., Barbosa, W. L. R., \& Vincieri, F. F. (2004). Polyphenolic constituents of fruit pulp of Euterpe oleraceae Mart. (açaí palm). Chromatographia, 59, 739-743.

Gómez-Cortés, P., Frutos, P., Mantecón, A. R., Juárez, M., Fuente, M. A., \& Hervás, G. (2008). Addition of olive oil to dairy ewe diets: Effect on milk fatty acid profile and animal performance. Journal of Dairy Science, 91, 3119-3127.

Gonthier, M. P., Donovan, J. L., Texier, O., Felgines, C., Remesy, C., \& Scalbert, A. (2003). Metabolism of dietary procyanidins in rats. Free Radicals Biology \& Medicine, 35, $837-844$

Hartzfeld, P. W., Forkner, R., Hunter, M. D., \& Hagerman, A. E. (2002). Determination of hydrolysable tannins (gallotannins and ellagitannins) after reaction with potassium iodate. Journal of Agricultural and Food Chemistry, 50, 1785-1790.

Huang, D., Ou, B., \& Prior, R. L. (2005). The chemistry behind antioxidant capacity assays. Journal of Agricultural and Food Chemistry, 53, 1841-1856.

Jensen, G. S., Wu, X., Patterson, K. M., Barnes, J., Carter, S. G., Scherwitz, L., et al. (2008) In Vitro and in Vivo antioxidant and anti-inflammatory capacities of an antioxidantrich fruit and berry juice blend. Results of a pilot and randomized, double-blinded, placebo-controlled, crossover study. Journal of Agricultural and Food Chemistry, 56, $8326-8333$

Jiménez-Escrig, A., Rincón, M., Pulido, R., \& Saura-Calixto, F. (2001). Guava fruit (Psidium guajava L.) as a new source of antioxidant dietary fiber. Journal of Agricultural and Food Chemistry, 49, 5489-5493.

Larrauri, J. A., Rupérez, P., \& Saura-Calixto, F. (1997). Effect of drying temperature on the stabilitity of polyphenols and antioxidant activity of red grape pomace peels. Journal of Agricultural and Food Chemistry, 45, 1390-1393.

Mahattanatawee, K., Manthey, J. A., Luzio, G., Talcott, S. T., Goodner, K., \& Baldwin, E. A. (2006). Total antioxidant activity and fiber content of select Florida-grown tropical fruits. Journal of Agricultural and Food Chemistry, 54, 7355-7363.

Menezes, E. M. S., Torres, A. T., \& Srur, A. U. S. (2008). Valor nutricional da polpa de açaí (Euterpe oleracea Mart) liofilizada. Acta Amazônica, 38, 311-316.

Mertens-Talcott, S. U., Rios, J., Jilma-Stohlawetz, P., Pacheco-Palencia, L. A., Meibohm, B. Talcott, S. T., et al. (2008). Pharmacokinetics of anthocyanins and antioxidant effects after the consumption of anthocyanin-rich açai juice and pulp (Euterpe oleracea Mart.) in human healthy volunteers. Journal of Agricultural and Food Chemistry, 56, 7796-7802.

Ou, B., Hampsch-Woodill, M., \& Prior, R. L. (2001). Development and validation of an improved oxygen radical absorbance capacity assay using fluorescein as the flourescent probe. Journal of Agricultural and Food Chemistry, 49, 4619-4626.

Pacheco-Palencia, L. A., Mertens-Talcott, S., \& Talcott, S. T. (2008). Chemical composition, antioxidant properties, and thermal stability of a phytochemical enriched oil from açaí (Euterpe oleracea Mart.). Journal of Agricultural and Food Chemistry, 56, 4631-4636.

Pérez-Jiménez, J., Arranz, S., Tabernero, M., Díaz-Rubio, M. E., Serrano, J., Goñi, I., et al. (2008). Updated methodology to determine antioxidant capacity in plant foods, oils and beverages: Extraction, measurement and expression of results. Food Research International, 41, 274-285.

Pérez-Jiménez, J., \& Saura-Calixto, F. (2008). Anti-oxidant capacity of dietary polyphenols determined by ABTS assay: A kinetic expression of the results. International Journal of Food Science E Technology, 43, 185-191.

Pérez-Jiménez, J., Serrano, J., Tabernero, M., Arranz, S., Díaz-Rubio, M. E., García-Diz, L. et al. (2008). Effects of grape antioxidant dietary fiber on cardiovascular disease risk factors. Nutrition, 24, 646-653.

Pozo-Insfran, D. D., Percival, S. S., \& Talcott, S. T. (2006). Açaí (Euterpe oleracea Mart.) polyphenolics in their glycoside and aglycone forms induce apoptosis of HL-60 leukemia cells. Journal of Agricultural and Food Chemistry, 54, 1222-1229.

Pulido, R., Bravo, L., \& Saura-Calixto, F. (2000). Antioxidant activity of dietary polyphenols as determined by a modified ferric reducing antioxidant power assay. Journal of Agricultural and Food Chemistry, 48, 3396-3402.

Re, R., Pellegrini, N., Proteggente, A., Pannala, A., Yang, M., \& Rice-Evans, C. (1999). Antioxidant activity applying an improved ABTS radical cation decolorization assay. Free Radicals. Biology E Medicine, 26, 1231-1237.

Reed, J. D., McDowell, R. T. E., Van Soest, P. J., \& Horvath, P. R. J. (1982). Condensed tannins: A factor limiting the use of cassava forage. Journal of the Science of Food and Agriculture, 33, 213-220.

Ribeiro, J. C., Antunes, L. M. G., Aissa, A. F., Darin, J. D. C., Veridiana Rosso, V., Mercadante A. Z., et al. (2010). Evaluation of the genotoxic and antigenotoxic effects after acute and subacute treatments with açaí pulp (Euterpe oleracea Mart.) on mice using the erythrocytes micronucleus test and the comet assay. Mutation Research, 695, $22-28$.

Rufino, M. S. M., Alves, R. E., Brito, E. S., Pérez-Jiménez, J., Saura-Calixto, F., et al. (2010) Bioactive compounds and antioxidant capacities of 18 non-traditional tropical fruits from Brazil. Food Chemistry, 121, 996-1002.

Rufino, M. S. M., Alves, R. E., Brito, E. S., Perez-Jimezes, J., \& Saura-Calixto, F. D. (2009) Total phenolic content and antioxidant activity in acerola, açaí, mangaba and uvaia fruits by DPPH method. Acta Horticulturae, 841, 459-462.

Rufino, M. S. M., Alves, R. E., Brito, E. S., Silveira, M. R. S., \& Moura, C. F. H. (2009). Quality for fresh consumption and processing of some non-traditional tropical fruits from Brazil. Fruits, 64, 361-370.

Rufino, M. S. M., Fernandes, F. A. N., Alves, R. E., \& Brito, E. S. (2009). Free radicalscavenging behaviour of some north-east Brazilian fruits in a DPPH ${ }^{*}$ system. Food Chemistry, 114, 693-695.

Sánchez-Alonso, I., Jiménez-Escrig, A., Saura-Calixto, F., \& Borderías, A. J. (2006). Effect of grape antioxidant dietary fiber on the prevention of lipid oxidation in minced fish: Evaluation by different methodologies. Food Chemistry, 101, 372-378.

Sánchez-Moreno, C., Larrauri, J. A., \& Saura-Calixto, F. (1998). A procedure to measure the antiradical efficiency of polyphenols. Journal of the Science of Food and Agriculture, 76, 270-276.

Saura-Calixto, F. (1998). Antioxidant dietary fiber product: A new concept and a potential food ingredient. Journal of Agricultural and Food Chemistry, 48, 4303-4306.

Saura-Calixto, F., Garcia-Alonso, A., Goñi, I., \& Bravo, L. (2000). In vitro determination of the indigestible fraction in foods: An alternative to dietary fiber analysis. Journal of Agricultural and Food Chemistry, 48, 3342-3347.

Schauss, A. G., Wu, X., Prior, R. L., Ou, B., Patel, D., Huang, D., et al. (2006). Phytochemical and nutrient composition of the freeze-dried amazonian palm berry, Euterpe oleraceae Mart. (Acai). Journal of Agricultural and Food Chemistry, 54, 8598-8603.

Schreckinger, M. E., Lotton, J., Lila, M. A., \& Mejia, E. G. (2010). Berries from South America: A comprehensive review on chemistry, health potential, and commercialization. Journal of Medicinal Food, 13, 233-246.

Scott, R. W. (1979). Colorimetric determination of hexauronic acids in plant materials Analytical Chemistry, 51, 936-941.

Serrano, J., Goñi, I., \& Saura-Calixto, F. (2007). Food antioxidant capacity determined by chemical methods may underestimate the physiological antioxidant capacity. Food Research International, 40, 15-21.

Singleton, V. L., Orthofer, R., \& Lamuela-Raventós, R. M. (1999). Analysis of total phenols and other oxidation substrates and antioxidants by means of Folin-Ciocalteu reagent. Methods in Enzymology, 299, 152-178.

Southgate, D. A. (1969). Determination of carbohydrates in foods. Unavailable carbohydrates. Journal of the Science of Food and Agriculture, 20, 331-335.

Souza, M. C., Figueiredo, R. W., Maia, G. A., Alves, R. E., Brito, E. S., Moura, C. F. H., et al. (2009). Bioactive compounds and antioxidant activity on fruits from different açaî (Euterpe oleracea Mart) progenies. Acta Horticulturae, 841, 455-458.

Spiller, G. A. (2001). Handbook of dietary fiber in human nutrition. Boca Ratón: CRC Press.

Wong, J. M., Souza, R., Kendall, C. W., Emam, A., \& Jenkins, D. J. (2006). Colonic health: Fermentation and short-chain fatty acids. Journal of Clinical Gastroenterology, 40, $235-243$. 